\title{
Pathological Features of Polyneuropathy in Three Dogs
}

\author{
Masaya TSUBOI ${ }^{1)}$, Kazuyuki UCHIDA ${ }^{1) *}$, Tetsuya IDE ${ }^{1)}$, Mizue OGAWA ${ }^{1)}$, Takehiko INAGAKI ${ }^{2)}$, Shinji TAMURA ${ }^{3)}$, \\ Miyoko SAITO ${ }^{4)}$, James K. CHAMBERS ${ }^{1)}$ and Hiroyuki NAKAYAMA ${ }^{1)}$ \\ ${ }^{1)}$ Department of Veterinary Pathology, Graduate School of Agricultural and Life Sciences, The University of Tokyo, 1-1-1 Yayoi, Bunkyo- \\ ku, Tokyo 113-8657, Japan \\ ${ }^{2)}$ Department of Neurology, Japan Animal Referral Medical Center, 2-5-8 Kuji, Takatsu-ku, Kawasaki-shi, Kanagawa 213-0032, Japan \\ ${ }^{3)}$ Tamura Animal Clinic, 7-16 Saeki-ku, Hiroshima-shi, Hiroshima 731-5100, Japan \\ 4) Department of Surgery II, School of Veterinary Medicine, Azabu University, 1-17-71 Fuchinobe, Chuo-ku, Sagamihara-shi, Kanagawa \\ 229-8501, Japan
}

(Received 16 May 2012/Accepted 18 October 2012/Published online in J-STAGE 1 November 2012)

ABSTRACT. Canine polyneuropathy is a neurological disorder characterized by a dysfunction of multiple peripheral nerves. The etiology of the disease is diverse; it may occur in cases of infectious, immune-mediated, or hereditary conditions or in association with endocrinopathy, neoplasm, or chemical intoxication. It is often difficult to determine the etiology through clinical symptoms. The aim of this study is to investigate pathological differences among three canine polyneuropathy cases with each presumably having a different etiology. Cases included a 13-month-old female border collie (Dog No.1), a 21-month-old male chihuahua (Dog No.2) and an 11-year-old male beagle (Dog No.3). Clinical examinations revealed hindlimb ataxia and sensory loss in Dog No.1, forelimb paralysis and vertebral pain in Dog No.2, and paddling-gait and hypothyroidism in Dog No.3. Histopathologically, axonal swelling and pale myelin were observed in Dog No.1. Giant axons mimicking giant axonal neuropathy were obvious in Dog No.2. Dog No.3 showed atrophic axons and severe interstitial edema. Distributions of peripheral nerve lesions coincided with respective clinical symptoms. According to their clinical and pathological features, Dogs No.1 and No.2 were suspected of hereditary polyneuropathy, while Dog No.3 seemed to have hypothyroidism-associated polyneuropathy. As each case demonstrated unique pathological features, different pathogeneses of peripheral nerve dysfunction were suggested.

KEY WORDS: canine, congenital, hypothyroidism, polyneuropathy.

doi: 10.1292/jvms.12-0224; J. Vet. Med. Sci. 75(3): 327-335, 2013

Polyneuropathy in dogs is a neurological disorder characterized by a dysfunction of multiple peripheral nerves. Initial symptoms of the disease are a lack of coordination and instability, and often progress to decreased reflexes and muscle tone, paralysis, and sensory deficits [45]. Electromyographic evidence of denervation and decreased nerve conduction velocity has been observed in affected nerves [45]. Somatic nerve dysfunctions are most predominant, and autonomic nerves may also be affected. As autonomic dysfunction may lead to laryngeal or pharyngeal paralysis, aspiration pneumonia is frequently diagnosed as a cause of death in canine polyneuropathy cases $[6,16,26,32,46]$.

Several etiologies of polyneuropathy in dogs have been previously proposed. In some cases, the disease occurs in association with Neospora caninum infection [10] or some immune-mediated diseases, such as systemic lupus erythematosus [11]. Primary autoimmune diseases against peripheral nerve myelin may also lead to the disease [1, 51]. Some seem to occur in specific breeds, indicating that

\footnotetext{
*Correspondence to: Uchida, K., Department of Veterinary Pathology, Graduate School of Agricultural and Life Sciences, The University of Tokyo, 1-1-1 Yayoi, Bunkyo-ku, Tokyo 113-8657, Japan. e-mail:auchidak@mail.ecc.u-tokyo.ac.jp

(C)2013 The Japanese Society of Veterinary Science
}

hereditary, familial or breed-associated factors are related to the etiology of the disease [17]. It may also be associated with endocrinopathy including diabetes mellitus [27, 34, 47] and hypothyroidism [25, 49], intoxication of n-hexane [37] or acrylamide [20], administration of cisplatin [36] or vincristine [21], or paraneoplastic syndromes in cases of insulinoma [3,5], multicentric lymphoma [5], or disseminated carcinoma [5]. It is often difficult to distinguish the etiology of this disease through clinical symptoms.

The distribution of lesions (i.e. motor or sensory, distal or proximal, anterior or posterior and symmetric or asymmetric) is useful for etiology-based classification of polyneuropathy $[7,8,10]$. In the human-inherited polyneuropathy, CharcotMarie-Tooth (CMT) disease, classification is established according to lesion distribution, age onset, progression speed and pathological features [18], and a number of genetic mutations have been identified in respective subtypes [7, 43]. In contrast, little information on genetic factors has been accumulated in canine-inherited polyneuropathy [8]. So far, canine-inherited polyneuropathy has been reported in 22 breeds, but underlying genetic defects are not yet confirmed in most breeds $[8,17]$.

The aim of this study is to investigate pathological differences among three cases of canine polyneuropathy with each presumably having a different etiology. Possible pathogenesis and respective etiologies of each case are discussed. 


\section{MATERIALS AND METHODS}

Cases: Three dogs were examined; Dog No.1 was a 13-month-old female border collie, Dog No.2 was a 21-month-old male chihuahua and Dog No.3 was an 11-year-old male beagle. Clinical features of these cases are summarized in Table 1.

Dog No.1 showed progressive hind limb ataxia at the age of 3 months, and started chewing her front paw. Ataxia then spread to all 4 limbs. Spinal reflexes were normal to reduced in the hind limbs. Superficial sensation was not detected in sciatic and femoral areas of both sides of the distal hind limbs and in the radial area of both sides of the distal front limbs. Magnetic resonance imaging (MRI) of the spinal cord and cerebrospinal fluid (CSF) examination showed no specific findings. Ataxia gradually progressed, and the dog developed megaesophagus at the age of 12 months. The dog suddenly died 1 month after the onset of megaesophagus.

Dog No.2 was presented to the veterinary hospital 2 months prior to his death with a chief complaint of crying when held in his owner's arms. One month after the initial symptom, the dog exhibited salivation and a pitter-patter gait. Further clinical examination revealed a reduced bilateral palpebral reflex, persistent prolapse of the penis, and vertebral pain induced by manual compression. MRI and computerized tomography (CT) of the entire body showed no specific findings. Thyroid hormone levels were normal, and anti-acetylcholine receptor antibody was not detected in the serum. Tandem mass spectrometry used for the diagnosis of inherited metabolic disorders was conducted, but no specific information was obtained. Although the dog was treated with corticosteroids and vitamin supplements, symptoms did not improve. The forelimbs gradually became paralyzed, and atrophy of the forelimb muscle was marked. Finally, the dog exhibited epileptiform seizures and died of respiratory failure.

Dog No.3 began to show a characteristic paddling gait at the age of 3 , wherein the distal palmar and plantar aspects of the feet flip forward at the impact to the ground. The dog also sank on these limbs during the impact. Two years after the onset of the first symptom, the dog presented to the veterinary hospital with a chief complaint of a wobbling gait. The dog exhibited bradycardia at the initial visit, and neurological examination revealed a reduced postural reaction. MRI showed no specific findings. Biochemical examination at the age of 7 revealed low thyroxine (T4) and free T4 (fT4) concentrations (T4: $0.79 \mu \mathrm{g} / \mathrm{d} l$, relative to normal values of $>2.0$ $\mu \mathrm{g} / \mathrm{d} l$, and fT4: $0.08 n \mathrm{~g} / \mathrm{d} l$, relative to normal values of $>0.6$ $n \mathrm{~g} / \mathrm{d} l$ ). Thus, the dog was diagnosed with hypothyroidism. The dog was treated with thyroid hormone, but symptoms gradually developed. The dog began to present difficulty in walking at the age of 9 . Using sensory nerve action potential examination, the dog was further diagnosed with sensory nerve predominant segmental demyelinative neuropathy at the age of 10, and was treated with an immune suppressor and prednisolone. The treatment, however, had no effect. Finally, the dog died of aspiration pneumonia at the age of 11 .

Antemortem biopsy and teased nerve fiber test: Antemortem biopsy and a teased nerve fiber test were conducted only in Dog No.1. Peripheral nerves (including the right common peroneal nerve and right caudal cutaneous antebrachial nerve) and the skin of the dorsal part of the right front paw were taken for biopsy.

Postmortem examination: Tissue samples were taken from the brain, spinal cord and nerve roots of the 3 dogs. Other main organs including the heart, lungs, liver, spleen, kidneys, alimentary tract, pituitary gland, thyroid glands, adrenal glands, ovaries and uterus were taken only from Dog No.1, because autopsies of the other dogs were performed at the veterinary hospitals. The trigeminal ganglion, stellate ganglion, brachial plexus, femoral obturator nerve, vagus nerve, biceps femoris muscle, temporal muscle and lingual muscle were also taken from Dog No.1. Sciatic and tibial nerves were taken from Dog No.3. All tissue samples were fixed in $10 \%$ neutral buffered formalin, processed routinely, embedded in paraffin wax, and sectioned at $4 \mu \mathrm{m}$. Sections were double-stained with luxol-fast blue (LFB) and hematoxylin-eosin (HE).

Immunohistochemistry: Primary antibodies used were mouse monoclonal anti-neurofilament (NF, pre-diluted, Dako, Glostrup, Denmark), rabbit polyclonal anti-peripheral myelin protein 22 (PMP22, 1:400, Sigma, St. Louis, MO, U.S.A.), rabbit polyclonal anti-periaxin (PRX, 1:250, Sigma) and rabbit polyclonal anti-Myelin protein zero (MPZ, 1:100, Abcam, Cambridge, UK). Immunohistochemistry was performed using Envision polymer reagent (Dako). Antigen retrieval was performed by heating sections in an autoclave at $121^{\circ} \mathrm{C}$ for $10 \mathrm{~min}$ in $10 \mathrm{mM}$ citrate buffer (pH6.0), except for NF immunohistochemistry. Sections were next incubated in $3 \%$ hydrogen peroxide $\left(\mathrm{H}_{2} \mathrm{O}_{2}\right)$-methanol at room temperature for 5 min to block endogenous peroxidase, in $8 \%$ skim milk-tris buffered saline (TBS) at $37^{\circ} \mathrm{C}$ for $40 \mathrm{~min}$ to avoid nonspecific reactions, and then with primary antibody at $4^{\circ} \mathrm{C}$ overnight. Sections were further incubated with

Table 1. Canine polyneuropathy cases examined

\begin{tabular}{cccccc}
\hline Case & Breed & Gender & Onset & Death & Major clinical signs \\
\hline Dog No.1 & Border collie & Female & $3 \mathrm{~m}$ & $1 \mathrm{y} 1 \mathrm{~m}$ & $\begin{array}{c}\text { Hind limb ataxia, pain sensability loss, megaesophagus, } \\
\text { chewing front paws, and aspiration pneumonia }\end{array}$ \\
Dog No.2 & Chihuahua & Male & $1 \mathrm{y} 7 \mathrm{~m}$ & $1 \mathrm{y} 9 \mathrm{~m}$ & $\begin{array}{c}\text { Salivation, bilateral eyelid reflex reduction, continuous penis } \\
\text { prolapse, ataxia, forelimb paralysis, and vertebral pain } \\
\text { Paddling-gait, bradycardia, hypothyroidism, walking } \\
\text { difficulty, and aspiration pneumonia }\end{array}$ \\
\hline
\end{tabular}


Envision horseradish peroxidase (HRP)-labeled mouse or rabbit polymer reagent (Dako) at $37^{\circ} \mathrm{C}$ for $60 \mathrm{~min}$. Reaction products were visualized with 3.3'-diaminobenzidine (DAB, Dojindo, Kumamoto, Japan) and $0.03 \% \mathrm{H}_{2} \mathrm{O}_{2}$ in TBS. Sections were counterstained with Mayer's hematoxylin. As a control, sections from dogs showing no clinical/pathological signs of polyneuropathy were used.

Quantitative analysis: NF-stained transverse sections of the lumber nerve root were used for quantitative analysis. Microscopic pictures of 2 randomly selected-areas of dorsal and ventral nerve roots were taken with a Nikon Digital Camera DXM1200F (Nikon, Tokyo, Japan) at a magnification of $\times 200$ with ACT-1 software (Nikon). The smallest diameters of respective NF-positive axons were then computed using Mac-Biophotonics ImageJ software. More than 1,000 fibers in each nerve root were measured.

\section{RESULTS}

Antemortem biopsy and the teased nerve fiber test: Antemortem peripheral nerve biopsy was conducted only in Dog No.1. The right common peroneal nerve, right caudal cutaneous antebrachial nerve, and peripheral nerves from the dorsal skin of the right front paw showed severe degeneration and denervation with both sensory and motor involvement (Data not shown). The teased nerve fiber test was also conducted only in Dog No.1. Neither Wallarian-like axonal degeneration nor regenerative changes were observed in the teased nerve fiber test (Data not shown).

Gross findings on necropsy: Details were available only in Dog No.1. Severe emaciation, multiple ulcerations on the bilateral hind limb paws, swelling of systemic lymph nodes, and aspiration pneumonia were observed. There were no specific findings in the gross appearance of the brain and spinal cord of all three cases.

Histopathological findings on necropsy: Major pathological lesions were located at nerve roots and/or distal peripheral nerves in all cases (Fig. 1A, 1B and 1C). Histopathological lesions and their distributions in peripheral nerves were different among cases (Table 2).

In Dog No.1, lesions were predominant at lumbar and sacral ventral nerve roots, and the major lesion was axonal swelling (Fig. 1D). Myelin stained with LFB was paler than usual at the central area of nerve roots. Axonal loss was not evident in any nerve roots of Dog No.1. Lesions in Dog No.2 were located mainly in cervical and thoracic nerve roots. Almost all axons were lost and lesions were replaced by dense fibrous connective tissues (Fig. $1 \mathrm{G}$ and $1 \mathrm{H}$ ). Lesions were asymmetric and randomly distributed. At the lumber level, axonal and myelin loss was milder than that at the cervical level, but multiple axonal swellings were observed at the unilateral sensory nerve root at L4 (Fig. 1E). Such swollen axons were roughly distorted and were huge (10 to $30 \mu \mathrm{m}$ as the shortest diameter). In Dog No.3, lesions were found at the cervical and lumber level of motor and sensory nerve roots, where diffuse axonal atrophy was evident. Severe endoneurial edema and mild fibrous connective tissue proliferation were associated with lesions (Fig. 1F). Lesions were more severe in sensory nerve roots than those in motor nerve roots. Inflammatory cell infiltration was not observed in any cases.

Distal peripheral nerves were also examined in Dogs No.1 and No.3. In Dog No.1, lesions of the femoral obturator nerve and brachial plexus were more severe than those of nerve roots. Severe axonal swelling, mild axonal loss, pale myelin and mild proliferation of collagen fibers were also observed (Fig. 1I). In Dog No.3, sural and tibial nerves showed a severe decrease in axons and loss of myelin. Most lesions were replaced with fibrous connective tissues (Fig. $1 \mathrm{~J})$.

Minor lesions were observed in the central nervous system (CNS), such as focal neuronal loss in the cerebral cortex of Dog No.2 and diffuse spheroid formation in the spinal cord of Dog No.3 (Data not shown).

Quantitative analysis: The axonal diameter of nerve roots was analyzed using NF-immunostained specimens (Fig. 2). In control cases, the shape of the histogram for the motor nerve root showed a "bimodal" pattern, which indicates the presence of large caliber fibers ranging from 6 to $8 \mu \mathrm{m}$, and small caliber fibers ranging from 1 to $3 \mu \mathrm{m}$ (Fig. $2 \mathrm{G}, 2 \mathrm{H}$ and 2I). In contrast, the number of large caliber fibers in the sensory nerve root was fewer than that in the motor nerve root (Fig. 2J, 2K and 2L). Therefore, the shape of the histogram showed a "triangular" pattern.

In Dog No.1, a bimodal pattern in motor nerve roots was still evident, but the distribution of the axonal diameter tended to shift to the right (larger area) (Fig. 2G). The distribution in the sensory nerve root showed a slight left shift (Fig. 2J). In Dog No.2, distribution in both motor and sensory nerves shifted to the left, and giant axons more than 15 $\mu \mathrm{m}$ were often observed in the sensory nerve root (Fig. $2 \mathrm{H}$ and $2 \mathrm{~K}$ ). In Dog No.3, the axonal distribution of both motor and sensory nerve roots markedly shifted to the left, and the regular "bimodal" pattern of the motor nerve root changed to a "triangular" pattern (Fig. 2I and 2L).

Immunohistochemistry for myelin components: Among 3 peripheral myelin components examined, PMP22 and PRX were strongly positive in the axonal surroundings. MPZ expression was limited to Dog No.1, and non-specific MPZ expressions were observed in the axons of Dogs No.2 and No.3 (data not shown).

\section{DISCUSSION}

Severe degenerative changes were broadly distributed in the peripheral nervous system (PNS) of the three present cases, while significant pathological changes were not observed in the CNS. Thus, the present cases were diagnosed as canine polyneuropathy. Interestingly, the distributions and pathological features of lesions were different among the cases. This fact indicates different pathogeneses in the respective cases.

According to clinical histories and pathological findings, Dogs No.1 and No.2 were suspected of hereditary polyneuropathy. Both dogs were young at the onset of the disease and took long-standing courses until death. Such features are 


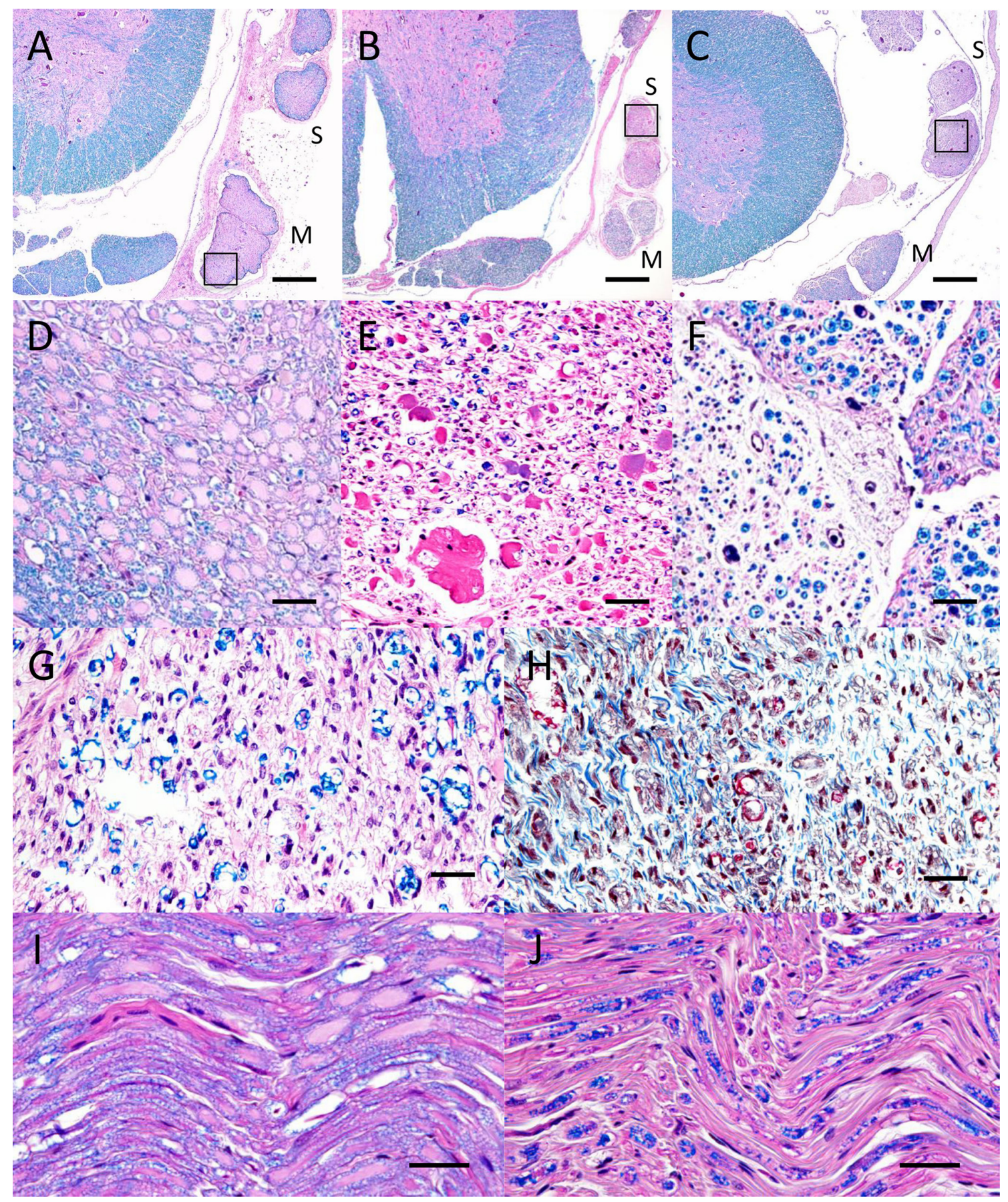

Fig. 1. (A-C): Low magnification of the lumber cord and associated nerve roots of Dogs No.1 (A), No.2 (B) and No.3 (C). LFBHE stain. Bar $=500 \mu \mathrm{m}$. In all cases, lesions were located in sensory (S) and/or motor (M) nerve roots. (D-F): Higher magnification of the boxes shown in (A-C). LFB-HE stain. Bar=20 $\mu \mathrm{m}$. (D) Axons in Dog No.1 were severely swollen, and surrounding myelin was pale stained with LFB. (E) Dog No.2 had giant axons, and surrounding myelin was lost. (F) Axons in Dog No.3 were small in diameter, and severe edema was observed in the interstitium. $(\mathrm{G}, \mathrm{H})$ : High magnification of the cervical sensory nerve root in Dog No.2. LFB-HE stain $(\mathrm{G})$ and Masson's trichrome stain $(\mathrm{H})$. Bar=20 $\mu \mathrm{m}$. Severe edema and mild fibrous connective tissue proliferation were associated with severe axonal loss. (I, J): High magnification of distal peripheral nerves of Dogs No.1 (I) and No.3 (J). LFB-HE stain. Bar=20 $\mu \mathrm{m}$. (I) Femoral obturator nerve in Dog No.1 had more severe degeneration in both axons and myelin than that in nerve roots. $(\mathrm{J})$ Axons and myelin in the tibial nerve of Dog No.3 were severely lost, and most lesions were replaced with connective tissue. 
Table 2. Histological lesions in the cervical, thoracic, lumber and sacral nerve roots

\begin{tabular}{|c|c|c|c|c|c|c|}
\hline & \multicolumn{2}{|c|}{ Dog No.1 } & \multicolumn{2}{|c|}{ Dog No.2 } & \multicolumn{2}{|c|}{ Dog No.3 } \\
\hline & Motor & Sensory & Motor & Sensory & Motor & Sensory \\
\hline \multicolumn{7}{|l|}{ Cervical } \\
\hline Axonal swelling & - & + & - & - & - & - \\
\hline Axonal loss & - & - & +++ & +++ & ++ & +++ \\
\hline Myelin loss & + & + & +++ & +++ & ++ & ++ \\
\hline Edema & - & - & + & - & ++ & ++ \\
\hline Fibrosis & + & - & +++ & ++ & ++ & ++ \\
\hline \multicolumn{7}{|l|}{ Thoracic } \\
\hline Axonal swelling & ++ & - & - & - & ND & ND \\
\hline Axonal loss & - & - & ++ & + & ND & ND \\
\hline Myelin loss & + & - & +++ & +++ & ND & ND \\
\hline Edema & - & - & ++ & ++ & ND & ND \\
\hline Fibrosis & + & - & ++ & + & ND & ND \\
\hline \multicolumn{7}{|l|}{ Lumbar } \\
\hline Axonal swelling & +++ & - & - & +++ & - & - \\
\hline Axonal loss & - & - & + & + & - & ++ \\
\hline Myelin loss & ++ & + & ++ & ++ & - & ++ \\
\hline Edema & - & - & + & + & + & +++ \\
\hline Fibrosis & - & - & + & + & ++ & ++ \\
\hline \multicolumn{7}{|l|}{ Sacral } \\
\hline Axonal swelling & +++ & - & - & - & ND & ND \\
\hline Axonal loss & - & - & - & - & ND & ND \\
\hline Myelin loss & ++ & ++ & - & - & ND & ND \\
\hline Edema & - & - & - & - & ND & ND \\
\hline Fibrosis & - & - & - & - & ND & ND \\
\hline
\end{tabular}

-: None, +: Faint, ++: Mild, +++: Moderate, and ND: No data.

characteristic of inherited polyneuropathy [17]. Other causes such as chemical or drug intoxication were rejected, because of their clinical histories. Infectious or autoimmune diseases were also rejected, because inflammatory cell infiltration was not associated with the present cases. Endocrinopathy was not detected through the antemortem blood test, and neoplasm hardly occurs at their ages. Therefore, breedassociated congenital factors are the most likely etiology in the 2 dogs.

Breed-associated polyneuropathy in border collies has been previously reported in the United Kingdom [50], Belgium [48], and North America [22]. Although there was no information concerning the familial history of the present border collie dog (Dog No.1), clinical signs were almost consistent with those of previous cases [22, 48, 50]: the onset of disease occurred at 2 to 5 months old, and erosion in the hind footpad was observed. Pathological findings of the antemortem biopsy (i.e. severe degeneration and denervation) were also similar to those of previous reports [22, 48, 50]. Taking these similarities into account, it is likely that Dog No.1 suffered border collie polyneuropathy.

In spite of clinical and antemortem pathological similarities, postmortem pathological features in Dog No.1 were quite different from those of previous reports. Axonal swelling and pale myelin seen in the present case have never been mentioned in previous reports. This intriguing phenomenon may be explained by a difference in examined regions between past and present cases; pathological features previ- ously described are confined to the distal end of peripheral nerves, and more proximal regions, as in the present case, were not examined in previous reports.

The disorder in the border collie was previously called "sensory neuropathy", because initial symptoms were predominantly located at sensory nerves $[48,50]$. Harkin et al. [22] proposed the name "sensory and motor neuropathy", because motor nerves were also involved in his case. Lesions of the present case support Harkin's opinion, because both motor and sensory nerves were impaired.

Giant axons observed in the dorsal lumber root of Dog No. 2 were variable in size and had an irregular shape. They seemed to be different from the axonal swelling observed in Dog No.1, but were similar to lesions observed in "giant axonal neuropathy" (GAN) in humans [31] and German shepherds [13, 14, 19]. However, the distribution of giant axons in Dog No.2 was different from that in previous GAN cases. While the distribution of giant axons in GAN has been reported in both central and peripheral nervous systems [13, $14,19]$, these CNS lesions were not found in Dog No.2. Moreover, hind limbs were mostly affected in GAN cases, while forelimbs were mostly affected in Dog No.2. Combining these differences, we suggest that the present case of Dog No.2 is a unique congenital polyneuropathy newly emerged in the chihuahua.

Although peripheral nerves were mostly impaired in Dog No.2, a minor lesion was also observed in the CNS; there was focal neuron loss at the cerebral cortex. This pathologic 

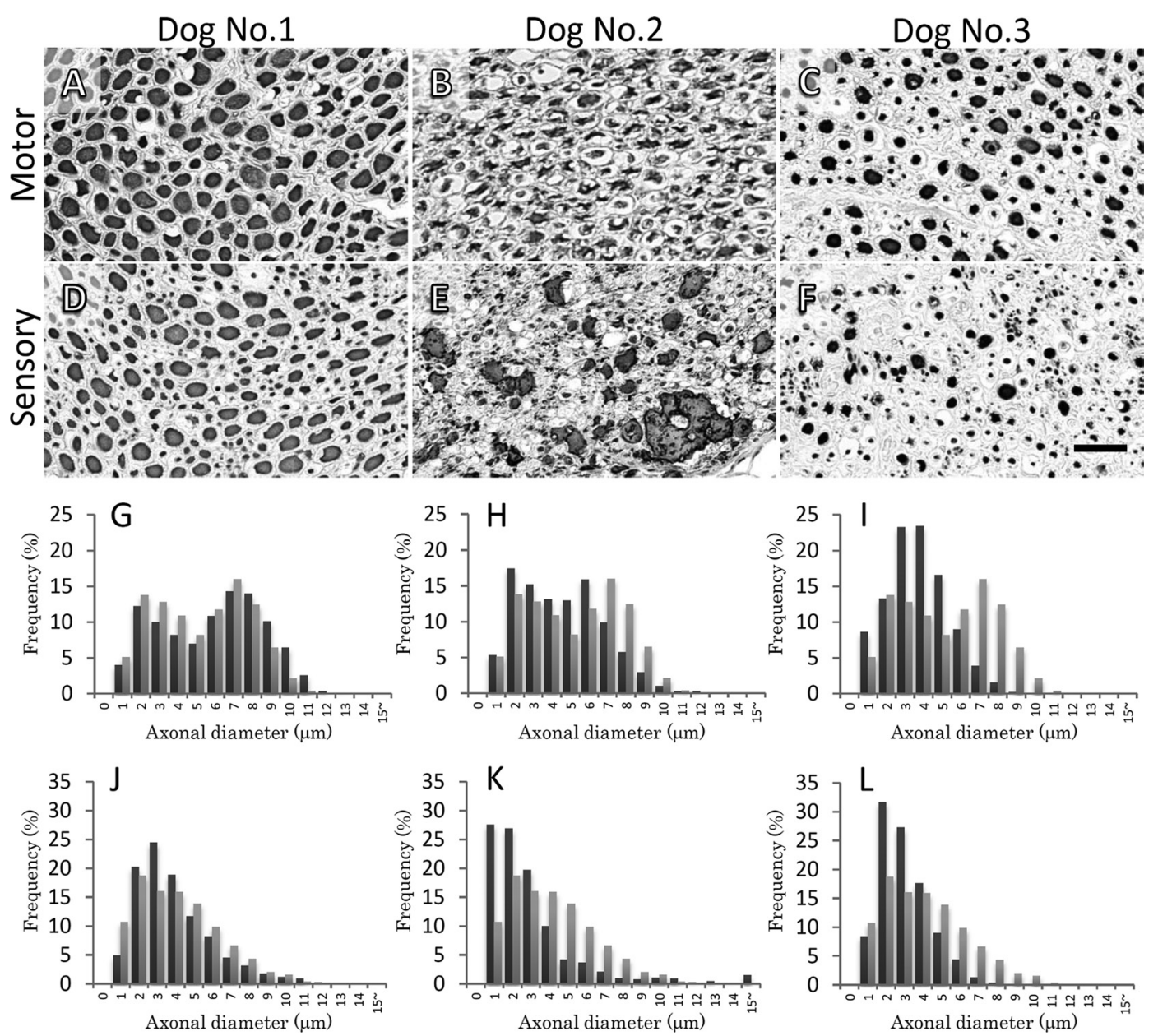

Fig. 2. (A-F): Transverse sections of lumber motor (A-C) and sensory (D-F) nerve roots. Anti-neurofilament immunohistochemistry. Bar $=20 \mu \mathrm{m}$. Axonal diameters were measured using Mac-Biophotonics ImageJ software. (G-L): Axonal diameter distributions of motor (G-I) and sensory (J-L) nerve roots of Dogs No.1 (G and J; shown in dark bars), No.2 (H and K; shown in dark bars), No.3 (I and L; shown in dark bars), and control dogs (G-L; shown in light bars), respectively.

feature correlates with antemortem epileptic symptoms. On another hand, there were some discrepancies between clinical and pathological appearances in Dog No.2; the dog clinically showed palpebral reflex reduction, but a pathological lesion related to the reflex was not observed in the CNS. The neural circuit of the palpebral reflex consists of the trigeminal nerve, mesencephalon and facial nerve, but the CNS part of this neural circuit was not impaired in this dog. Thus, we suspect that the clinical symptom seemed to be attributed to cranial nerve dysfunction. Nevertheless, we could not evaluate pathological changes in these cranial nerves, because we failed to investigate them on necropsy.

In human CMT disease, more than 30 genes have been identified as causal genes [7, 43]. Some of those genes encode constructive proteins of peripheral myelin sheaths. MPZ, for example, is an integral membrane glycoprotein and is a major component of peripheral nerve myelin [39]. MPZ guides the wrapping process in Schwann cells and ultimately compacts adjacent lamellae [39]. More than 120 mutations in the $M P Z$ gene have been identified in CMT type 1B, which is demyelinative neuropathy [23], or in CMT types 2I and 2J, which are axonal neuropathies [2, 28]. Likewise, PRX and PMP22 protein construct peripheral myelin sheaths, and genetic failures in these proteins are the causes of CMT type $1 \mathrm{~A}$ and type $4 \mathrm{~F}$, respectively [30,41]. Altered amino acid sequences of these constructive proteins lead to a failure to interact properly with other myelin components, and results in myelin disruption.

On another hand, the genetic background of canine hereditary polyneuropathy remains unclear in most breeds. Recently, Drögemüller et al. [12] identified a deletion in the $\mathrm{N}$-myc downstream regulated gene 1 (NDRG1) gene in greyhound polyneuropathy. It was recognized as the first genetically characterized canine model of human CMT disease, as the NDRG1 mutation had been identified in human CMT disease type 4D. It may offer an opportunity to gain further 
insight into the pathobiology and therapy of human $N D R G 1$ associated CMT disease.

We probatively tried to investigate the genetic causes of the 2 present cases that were suspected of hereditary polyneuropathies. Using immunohistochemical methods, we evaluated PMP22, PRX and MPZ protein expressions in intact peripheral nerves. Among them, PMP22 and PRX were expressed normally in the peripheral myelin sheath in all cases. Therefore, genes encoding these proteins do not seem to be responsible for the onset of the disease. MPZ expression in the myelin sheath was observed only in Dog No.1, and only faint axonal expression was observed in Dogs No.2 and No.3. Faint axonal expression was also observed in several samples from control cases. Therefore, we concluded that differences in expression may be due to respective fixation conditions, not $M P Z$ gene mutations.

Contrary to Dogs No.1 and No.2, Dog No.3 was suspected to have acquired neuropathy with an association of hypothyroidism. Clinical signs of tetraparesis and postural reaction dysfunction in Dog No.3 were consistent with those of previous reports of canine hypothyroid polyneuropathy $[4,24,25,42,49]$. Even though hypothyroidism is a common endocrinopathy of dogs and has been blamed for generalized peripheral neuropathy, there is currently insufficient objective evidence to prove a causal relationship between hypothyroidism and acquired polyneuropathy in dogs [11]. Previously, Rossmeisl [42] experimentally induced chronic hypothyroidism in dogs using radioactive iodine administration, and evaluated clinical and electrophysiologic effects on multiple peripheral nerves. The previous report succeeded in replicating the hypothyroid condition, but failed to detect any adverse clinical or electrophysiologic peripheral neuropathic changes. Another report of experimentally induced hypothyroidism in the rat showed similar results [40]. Thus, it is likely that other factors may be required for the development of hypothyroid polyneuropathy.

The pathological features of hypothyroid polyneuropathy have not been identified in dogs. In humans [33, 35, 38, 44], it has been reported that demyelination and interstitial edema may be associated with axonal atrophy in a long-standing course of hypothyroidism. The bimodal pattern is lost in the histogram of peripheral nerve axons in human hypothyroid neuropathy [44]. These features are very similar to those in Dog No.3.

There are some hypotheses that explain the pathomechanism of human hypothyroid polyneuropathy. Altered Schwann cell metabolism may cause mucinous deposition, which results in nerve entrapment and demyelination $[9,15$, 29]. Severe metabolic defects in neurons may also disturb axonal transport and lead to axonal atrophy [9, 15, 29]. Vascular nerve damage secondary to hypothyroid-induced alternations in the blood-nerve barrier may also cause demyelination $[9,15,29]$. Considering these pathologic similarities, hypothyroid polyneuropathy in dogs may have the same pathogenesis as that of humans.

In conclusion, the present paper describes the pathological features of three canine cases of polyneuropathy. All 3 cases exhibited unique pathologic features, and the respec- tive etiologies seemed different from each other. The cases of the border collie and chihuahua were suspected of inherited polyneuropathy, with each perhaps having different genetic factors, while the case of the beagle was presumably associated with hypothyroidism. This paper presents new aspects of the respective polyneuropathies. In the case of the border collie, the pathologic appearance of peripheral nerves showed quite different features from that of previous reports. The case of the chihuahua indicates a newlyemerged hereditary polyneuropathy, the features of which partly resemble GAN in German shepherd dogs. The case of the beagle presented a novel pathologic feature of canine hypothyroid polyneuropathy for the first time. Further studies are required to confirm respective pathogeneses of canine polyneuropathy.

\section{REFERENCES}

1. Alaedini, A., Sander, H. W., Hays, A. P. and Latov, N. 2003. Antiganglioside antibodies in multifocal acquired sensory and motor neuropathy. Arch. Neurol. 60: 42-46. [Medline] [CrossRef]

2. Auer-Grumbach, M., Strasser-Fuchs, S., Robl, T., Windpassinger, C. and Wagner, K. 2003. Late onset Charcot-Marie-Tooth 2 syndrome caused by two novel mutations in the MPZ gene. Neurology 61: 1435-1437. [Medline] [CrossRef]

3. Bergman, P. J., Bruyette, D. S., Coyne, B. E., Shelton, G. D., Ogilvie, G. K., Munana, K. R. and Richter, K. P. 1994. Canine clinical peripheral neuropathy associated with pancreatic-islet cell-carcinoma. Prog. Vet. Neurol. 5: 57-62.

4. Bichsel, P., Jacobs, G. and Oliver, J. E. Jr. 1988. Neurologic manifestations associated with hypothyroidism in four dogs. $J$. Am. Vet. Med. Assoc. 192: 1745-1747. [Medline]

5. Braund, K. G., Mcguire, J. A., Amling, K. A. and Henderson, R. A. 1987. Peripheral neuropathy associated with malignant neoplasms in dogs. Vet. Pathol. 24: 16-21. [Medline]

6. Braund, K. G., Steinberg, H. S., Shores, A., Steiss, J. E., Mehta, J. R., Toiviokinnucan, M. and Amling, K. A. 1989. Laryngeal paralysis in immature and mature dogs as one sign of a more diffuse polyneuropathy. J. Am. Vet. Med. Assoc. 194: 1735-1740. [Medline]

7. Burns, T. M. and Mauermann, M. L. 2011. The evaluation of polyneuropathies. Neurology 76: S6-S13. [Medline] [CrossRef]

8. Coates, J. R. and O'Brien, D. P. 2004. Inherited peripheral neuropathies in dogs and cats. Vet. Clin. North Am. Small Anim. Pract. 34: 1361-1401. [Medline] [CrossRef]

9. Cruz, M. W., Tendrich, M., Vaisman, M. and Novis, S. A. 1996. Electroneuromyography and neuromuscular findings in 16 primary hypothyroidism patients. Arq. Neuropsiquiatr. 54: 12-18. [Medline] [CrossRef]

10. Cuddon, P., Lin, D. S., Bowman, D. D., Lindsay, D. S., Miller, T. K., Duncan, I. D., Delahunta, A., Cummings, J., Suter, M., Cooper, B., King, J. M. and Dubey, J. P. 1992. Neospora caninum infection in English Springer Spaniel littermates. Diagnostic evaluation and organism isolation. J. Vet. Intern. Med. 6: 325-332. [Medline] [CrossRef]

11. Cuddon, P. A. 2002. Acquired canine peripheral neuropathies. Vet. Clin. North Am. Small Anim. Pract. 32: 207-249. [Medline] [CrossRef]

12. Drögemüller, C., Becker, D., Kessler, B., Kemter, E., Tetens, J., Jurina, K., Jäderlund, K. H., Flagstad, A., Perloski, M., Lindblad-Toh, K. and Matiasek, K. 2010. A deletion in the N-myc 
downstream regulated gene 1 (NDRG1) gene in Greyhounds with polyneuropathy. PLoS ONE 5: e11258. [Medline] [CrossRef]

13. Duncan, I. D. and Griffiths, I. R. 1979. Peripheral nervous system in a case of canine giant axonal neuropathy. Neuropathol. Appl. Neurobiol. 5: 25-39. [Medline] [CrossRef]

14. Duncan, I. D. and Griffiths, I. R. 1981. Canine giant axonal neuropathy; some aspects of its clinical, pathological and comparative features. J. Small Anim. Pract. 22: 491-501. [Medline] [CrossRef]

15. El-Salem, K. and Ammari, F. 2006. Neurophysiological changes in neurologically asymptomatic hypothyroid patients: a prospective cohort study. J. Clin. Neurophysiol. 23: 568-572. [Medline] [CrossRef]

16. Gabriel, A., Poncelet, L., Van Ham, L., Clercx, C., Braund, K. G., Bhatti, S., Detilleux, J. and Peeters, D. 2006. Laryngeal paralysis-polyneuropathy complex in young related Pyrenean mountain dogs. J. Small Anim. Pract. 47: 144-149. [Medline] [CrossRef]

17. Granger, N. 2011. Canine inherited motor and sensory neuropathies: An updated classification in 22 breeds and comparison to Charcot-Marie-Tooth disease. Vet. J. 188: 274-285. [Medline] [CrossRef]

18. Grant, I. A. and Benstead, T. J. 2005. Differential diagnosis of polyneuropathy. pp. 1163-1180. In: Peripheral Neuropathy, 4th ed. (Dyck, P. J. and Thomas, P. K. eds.), Elsevier, Philadelphia.

19. Griffiths, I. R. and Duncan, I. D. 1979. The central nervous system in canine giant axonal neuropathy. Acta Neuropathol. 46: 169-172. [Medline] [CrossRef]

20. Gupta, R. P. and Abou-Donia, M. B. 1996. Alterations in the neutral proteinase activities of central and peripheral nervous systems of acrylamide-, carbon disulfide-, or 2,5-hexanedionetreated rats. Mol. Chem. Neuropathol. 29: 53-66. [Medline] [CrossRef]

21. Hamilton, T. A., Cook, J. R. Jr., Braund, K. G., Morrison, W. B. and Mehta, J. R. 1991. Vincristine-induced peripheral neuropathy in a dog. J. Am. Vet. Med. Assoc. 198: 635-638. [Medline]

22. Harkin, K. R., Cash, W. C. and Shelton, G. D. 2005. Sensory and motor neuropathy in a Border Collie. J. Am. Vet. Med. Assoc. 227: 1263-1265. [Medline] [CrossRef]

23. Hayasaka, K., Himoro, M., Sato, W., Takada, G., Uyemura, K., Shimizu, N., Bird, T. D., Conneally, P. M. and Chance, P. F. 1993. Charcot-Marie-Tooth neuropathy type 1B is associated with mutations of the myelin P0 gene. Nat. Genet. 5: 31-34. [Medline] [CrossRef]

24. Indrieri, R. J., Whalen, L. R., Cardinet, G. H. and Holliday, T. A. 1987. Neuromuscular abnormalities associated with hypothyroidism and lymphocytic thyroiditis in three dogs. J. Am. Vet. Med. Assoc. 190: 544-548. [Medline]

25. Jaggy, A., Oliver, J. E., Ferguson, D. C., Mahaffey, E. A. and Glausjun, T. 1994. Neurological manifestations of hypothyroidism: a retrospective study of 29 dogs. J. Vet. Intern. Med. 8: 328-336. [Medline] [CrossRef]

26. Jeffery, N. D., Talbot, C. E., Smith, P. M. and Bacon, N. J. 2006. Acquired idiopathic laryngeal paralysis as a prominent feature of generalised neuromuscular disease in 39 dogs. Vet. Rec. 158: 17-21. [Medline] [CrossRef]

27. Johnson, C. A., Kittleson, M. D. and Indrieri, R. J. 1983. Peripheral neuropathy and hypotension in a diabetic dog. J. Am. Vet. Med. Assoc. 183: 1007-1009. [Medline]

28. Kabzińska, D., Korwin-Piotrowska, T., Dreschler, H., Drac, H., Hausmanowa-Petrusewicz, I. and Kochański, A. 2007. Late-onset Charcot-Marie-Tooth type 2 disease with hearing impairment associated with a novel Pro105Thr mutation in the MPZ gene Am. J. Med. Genet. A. 143A: 2196-2199. [Medline] [CrossRef]

29. Khedr, E. M., El Toony, L. F., Tarkhan, M. N. and Abdella, G. 2000. Peripheral and central nervous system alterations in hypothyroidism: electrophysiological findings. Neuropsychobiology 41: 88-94. [Medline] [CrossRef]

30. Kijima, K., Numakura, C., Shirahata, E., Sawaishi, Y., Shimohata, M., Igarashi, S., Tanaka, T. and Hayasaka, K. 2004. Periaxin mutation causes early-onset but slow-progressive CharcotMarie-Tooth disease. J. Hum. Genet. 49: 376-379. [Medline] [CrossRef]

31. Koch, T., Schultz, P., Williams, R. and Lampert, P. 1977. Giant axonal neuropathy: a childhood disorder of microfilaments. Ann. Neurol. 1: 438-451. [Medline] [CrossRef]

32. MacPhail, C. M. and Monnet, E. 2001. Outcome of and postoperative complications in dogs undergoing surgical treatment of laryngeal paralysis: 140 cases (1985-1998). J. Am. Vet. Med. Assoc. 218: 1949-1956. [Medline] [CrossRef]

33. Meier, C. and Bischoff, A. 1977. Polyneuropathy in hypothyroidism. Clinical and nerve biopsy study of 4 cases. J. Neurol. 215: 103-114. [Medline] [CrossRef]

34. Misselbrook, N. G. 1987. Peripheral neuropathy in diabetic bitch. Vet. Rec. 121: 287. [Medline] [CrossRef]

35. Nemni, R., Bottacchi, E., Fazio, R., Mamoli, A., Corbo, M., Camerlingo, M., Galardi, G., Erenbourg, L. and Canal, N. 1987. Polyneuropathy in hypothyroidism: clinical, electrophysiological and morphological findings in four cases. J. Neurol. Neurosurg. Psychiatry 50: 1454-1460. [Medline] [CrossRef]

36. Ongerboer de Visser, B. W. and Tiessens, G. 1985. Polyneuropathy induced by cisplatin. Prog. Exp. Tumor Res. 29: 190-196. [Medline]

37. Paulson, G. W. and Waylonis, G. W. 1976. Polyneuropathy due to n-hexane. Arch. Intern. Med. 136: 880-882. [Medline] [CrossRef]

38. Pollard, J. D., McLeod, J. G., Honnibal, T. G. and Verheijden, M. A. 1982. Hypothyroid polyneuropathy. Clinical, electrophysiological and nerve biopsy findings in two cases. J. Neurol. Sci. 53: 461-471. [Medline] [CrossRef]

39. Quarles, R. H., Macklin, W. B. and Morell, P. 2006. Myelin formation, structure, and biochemistry, in basic neurochemistry: molecular, cellular and medical aspects. pp. 51-71., In: Basic Neurochemistry: Molecular, Cellular, and Medical Aspects, 7th ed. (Siegel, G. J., Albers, R. W., Brady, S. T. and Price, D. eds.), Academic Press Elsevier, New York.

40. Quattrini, A., Nemni, R., Marchettini, P., Fazio, R., Iannaccone, S., Corbo, M. and Canal, N. 1993. Effect of hypothyroidism on rat peripheral nervous system. Neuroreport 4: 499-502. [Medline] [CrossRef]

41. Rosen, S. A., Wang, H., Cornblath, D. R., Uematsu, S. and Hurko, O. 1989. Compression syndromes due to hypertrophic nerve roots in hereditary motor sensory neuropathy type I. Neurology 39: 1173-1177. [Medline] [CrossRef]

42. Rossmeisl, J. H. Jr. 2010. Resistance of the peripheral nervous system to the effects of chronic canine hypothyroidism. J. Vet. Intern. Med. 24: 875-881. [Medline] [CrossRef]

43. Saporta, A. S. D., Sottile, S. L., Miller, L. J., Feely, S. M. E., Siskind, C. E. and Shy, M. E. 2011. Charcot-Marie-Tooth disease subtypes and genetic testing strategies. Ann. Neurol. 69: 22-33. [Medline] [CrossRef]

44. Shirabe, T., Tawara, S., Terao, A. and Araki, S. 1975. Myxedematous polyneuropathy: a light and electron microscopic study of peripheral nerve and muscle. J. Neurol. Neurosurg. Psychiatry 38: 241-247. [Medline] [CrossRef] 
45. Taylor, S. M. 2009. Disorders of peripheral nerves and the neuromuscular junction. pp. 1055-1056. In: Small Animal Internal Medicine, 4th ed. (Nelson, R. W. and Couto, C. G. eds.), Elsevier, Philadelphia.

46. Thieman, K. M., Krahwinkel, D. J., Sims, M. H. and Shelton, G. D. 2010. Histopathological Confirmation of polyneuropathy in 11 dogs with laryngeal paralysis. J. Am. Anim. Hosp. Assoc. 46: 161-167. [Medline]

47. Towell, T. L. and Shell, L. C. 1994. Endocrinopathies that affect peripheral nerves of cats and dogs. Compend. Contin. Educ. Pract. Vet. 16: 157-161.

48. Vermeersch, K., Van Ham, L., Braund, K. G., Bhatti, S., Tshamala, M., Chiers, K. and Schrauwen, E. 2005. Sensory neuropathy in two Border collie puppies. J. Small Anim. Pract. 46: 295-299. [Medline] [CrossRef]

49. Vitale, C. L. and Olby, N. J. 2007. Neurologic dysfunction in hypothyroid, hyperlipidemic Labrador Retrievers. J. Vet. Intern. Med. 21: 1316-1322. [Medline] [CrossRef]

50. Wheeler, S. J. 1987. Sensory Neuropathy in a Border Collie Puppy. J. Small Anim. Pract. 28: 281-289. [CrossRef]

51. Yuki, N., Ang, C. W., Koga, M., Jacobs, B. C., van Doorn, P. A., Hirata, K. and van der Meché, F. G. 2000. Clinical features and response to treatment in Guillain-Barré syndrome associated with antibodies to GM1b ganglioside. Ann. Neurol. 47: 314-321. [Medline] [CrossRef] 